\title{
Nat Natura: cenografia e ethos em perspectiva ergológica na comunicação organizacional
}

Nat Natura: scenography and ethos in an ergological perspective in the organizational communication

Nat Natura: escenografía y ethos en perspectiva ergológica en la comunicación organizacional

Ernani Cesar de Freitas

- Doutor em Letras pela Pontifícia Universidade Católica do Rio Grande do Sul (PUCRS).

- Mestre em Linguística Aplicada pela Universidade do Vale do Rio dos Sinos (Unisinos).

- $\quad$ Professor do Programa de Pós-Graduação em Processos e Manifestações Sociais da Universidade Feevale.

- $\quad$ Professor do Programa de Pós-Graduação em Letras da Universidade de Passo Fundo (UFP).

- E-mail: ernanic@feevale.br

\section{Fernando Simões Antunes Junior}

- Doutor em Comunicação Social pela PUCRS.

- Mestre em Comunicação Social pela PUCRS.

- $\quad$ Professor do Programa de Pós-Graduação em Processos e Manifestações Sociais da Universidade Feevale.

- $\quad$ E-mail: fernando.antunes@feevale.br

\section{Luis Henrique Boaventura}

- Doutor em Letras pela UPF.

- Mestre em Letras pela UPF.

- $\quad$ Pós-doutorando no Programa de Pós-Graduação em Letras da UPF.

- E-mail: luishboaventura@hotmail.com 


\section{Resumo}

Este artigo tem o objetivo de analisar a cenografia e o ethos mobilizados no Twitter pela brand persona Nat Natura sob as perspectivas da comunicação organizacional e da ergologia: linguagem e trabalho. Demonstramos que a empresa Natura \& Co., para angariar apoio e publicidade gratuita no Twitter, incorpora ao discurso organizacional sentidos construídos a partir de uma dinâmica autopoiética para apagar e substituir seu ethos de corporação por um de pessoa física com o qual seus clientes possam se identificar.

\section{PALAVRAS-CHAVE: ETHOS •CENOGRAFIA・ERGOLOGIA •COMUNICAÇÃO ORGANIZACIONAL・ATIVIDADE DE TRABALHO.}

\section{Abstract}

This article aims to analyze the scenography and ethos mobilized on Twitter by the brand persona Nat Natura from the perspectives of organizational communication and ergology: language and work. The results indicate that, to garner support and free advertising on Twitter, the company Natura \& Co. incorporates into the organizational discourse meanings constructed from an autopoietic dynamic, seeking to erase and replace its corporate ethos with an individual ethos to which its customers may identify themselves with.

KEYWORDS: ETHOS•SCENOGRAPHY •ERGOLOGY •ORGANIZATIONAL COMMUNICATION・WORK ACTIVITY.

\section{Resumen}

Este artículo tiene como objetivo analizar la escenografía y el ethos movilizado en Twitter por la marca persona Nat Natura desde las perspectivas de la comunicación organizacional y la ergología: lenguaje y trabajo. La empresa Natura \& Co., para obtener apoyo y publicidad gratuita en Twitter, incorpora al discurso organizacional los significados construidos a partir de una dinámica autopoiética para borrar y reemplazar su ethos corporativo a uno individual con el que sus clientes pueden identificarse. 


\section{INTRODUÇÃO}

A massificação das redes sociais nos últimos anos levou empresas à adoção de novas estratégias de comunicação com o público. Ao contrário, por exemplo, do Baixinho da Kaiser, personagem frequente nos comerciais brasileiros dos anos 1990 , as personagens virtuais Nat Natura, Lu do Magalu (Magazine Luiza) e Sam (Samsung) podem conversar com clientes em potencial em suas redes sociais. Elas postam memes, atualizações do seu cotidiano, comentam acontecimentos do mundo e respondem a usuários com toda a naturalidade possível, encenada por seus administradores. Há uma mudança em curso na relação entre empresas e público que carece de investigação, o que esperamos oferecer neste artigo.

Elaboramos, a partir dessa nova situação, a seguinte questão norteadora: Nat Natura opera a cenografia sob uma dinâmica autopoiética que simula dramáticas de uso do corpo-sipara projeção de um ethos com o qual os públicos da empresa devem se identificar. A partir dessa questão, nosso objetivo é analisar a cenografia e o ethos mobilizados no Twitter pela brand persona Nat Natura em interação com as noções de dinâmica autopoiética e dramáticas de uso do corpo-si.

No escopo do recorte teórico, que articula noções conceituais da comunicação organizacional com ergologia e análise do discurso, Nat Natura simula um corpo-si de "consultora da Natura", com dramáticas fabricadas para estreitar relações e angariar empatia com o público que a acompanha - pessoas reais que vivem dramáticas reais. Como contribuição, pretendemos oferecer uma base para análise, primeiro, de brand personas e, segundo, do comportamento em geral de contas oficiais de empresas nas redes sociais.

Esta pesquisa é descritiva, documental e bibliográfica, com caráter qualitativo. Nosso marco teórico começa por pressupostos da ergologia (Durrive, 2011; Schwartz, 2010), colocados em tela com preceitos da comunicação organizacional (Baldissera, 2017; Kunsch, 2017; Morgan, 2002) enquanto organizadora das regras e valores do mundo do trabalho. Na sequência, revisitamos conceitos da teoria enunciativo-discursiva de cunho sócio-histórico de Dominique Maingueneau (2005, 2020), especificamente os conceitos de cenografia e ethos do plano discursivo modo de enunciação. Por fim, selecionamos posts publicados pela conta da personagem na rede social Twitter para que sejam analisados à luz dos conceitos mobilizados.

\section{CENOGRAFIA, ERGOLOGIA E COMUNICAÇÃO ORGANIZACIONAL: REVISÃO E INTERFACE}

Este artigo pretende realizar uma interface entre a ergologia, com ênfase na relação entre linguagem e trabalho bem como nas dramáticas do uso de corpo-si (Schwartz, 2014), e a análise do discurso de linha francesa, acionando os conceitos de cenografia e de ethos como imagem de si (Maingueneau, 2020) para agregar perspectivas teóricas nos estudos da comunicação organizacional.

\section{Ergologia: as "dramáticas do uso de um corpo-si" na construção do discurso organizacional}

Numa perspectiva holística da comunicação organizacional enquanto fenômeno que tensiona significados entre diferentes sujeitos e todo o contexto político, econômico e social que os cercam (Kunsch, 2017), lançamos mão de pressupostos da ergologia para entender as origens de alguns processos complexos e sistêmicos dos quais resultam discursos organizacionais.

Do ponto de vista da atividade humana, a tensão entre o indivíduo e o coletivo ocupa o centro das atenções da abordagem ergológica (Schwartz; Echternacht, 2007). A engrenagem social, em parte uma cela para o indivíduo, em parte uma redoma milenar contra a aleatoriedade brutal da natureza, sustenta seu giro perpétuo através do sacrifício pontual e reiterado da 
individualidade em prol do bem-estar coletivo, o que o sujeito faz de bom grado, desde que seus pares realizem sacrifícios semelhantes para manutenção da ordem e da produtividade. Conforme Schwartz e Echternacht (2007, p.11), "do ponto de vista ergológico, a experiência humana no trabalho constitui-se através de uma permanente gestão de si mesmo, condição para o agir em competência nas situações produtivas".

De acordo com Durrive (2011, p.58), "a perspectiva ergológica e a didática profissional têm uma referência em comum, a ergonomia da atividade". Com a falência conceitual do modelo taylorista-fordista na segunda metade do século XX, viu-se surgir uma preocupação com a centralidade do ser humano na atividade de trabalho, implicando uma separação entre 0 trabalho prescrito e o trabalho real (Durrive, 2011). Para tratar dessa distância, bem como da relação entre linguagem e atividade de trabalho, foi estabelecido o campo interdisciplinar da ergologia. "Na ergologia, portanto, a análise é feita tanto quanto possível 'do ponto de vista daquele que trabalha' [...]" (Schwartz; Durrive, 2010, p.295). Trinquet (2010) argumenta que a ergologia é um "salto epistemológico". Trata-se de "[...] analisar sob quais condições [a atividade de trabalho] se realiza efetivamente [...]".

A revolução epistemológica da ergologia é colocada em aproximação com o olhar sistêmico de Niklas Luhmann (2016) sobre as ciências sociais ao utilizar o conceito de autopoiese para explicar a autodeterminação das organizações sociais, como se retroalimentam de significados a partir das interações entre os indivíduos que as constituem e o meio ao qual pertencem. Morgan (2002) revisita o conceito para alertar que dinâmicas autopoiéticas podem se tornar egocêntricas quando as organizações se findam no seu próprio universo, o que as impede de realizar trocas com o meio, ao mesmo tempo que podem entrar num processo evolutivo quando conectam seus padrões internos às mudanças muitas vezes aleatórias e caóticas do ambiente externo.

0 conceito de autopoiese foi rapidamente absorvido para compreender as dinâmicas e disputas de sentido nas organizações, em que os sujeitos interpelam e são interpelados pela cultura organizacional, originando sistemas de significação que darão sentido ao mundo em torno do qual estão agrupados (Baldissera, 2010). É a partir dessa dinâmica autopoiética - que pode ficar encarcerada na cultura da organização ou fluindo para padrões sistêmicos que reverberam nos ambientes externos que as organizações vão se reformulando e ressignificando a própria identidade (Morgan, 2002).

Há, no entanto, um aspecto seminal da contribuição de Schwartz (2014) à ergologia, foco do nosso recorte teórico: a noção de dramáticas do uso de um corpo-si, o que alude ao debate interno de valores e de normas que constituem o sujeito em relação ao meio em que ele se coloca e à atividade de trabalho que realiza. "Toda atividade industriosa é sempre uma 'dramática do uso de um corpo-si' (remetendo 'dramática' à necessidade contínua de travar debates com normas)" (Schwartz, 2014, p.159). 0 sujeito é, dessa forma, levado a um uso de si pelo outro conforme exigência da atividade, além de um uso de si por si mesmo de acordo com suas necessidades e valores pessoais, gerando um tensionamento de sentidos entre o indivíduo e a organização (Baldissera, 2010). De acordo com Schwartz (2014, p.261), a "arbitragem entre o uso de si por si e por outros implica forçosamente uma escolha, por ínfima que seja, incidente sobre a sequência de vida de outras pessoas [...]". Arbitrar esses conflitos leva ao que Schwartz (2014) chama de renormalizações, "decisões sempre parcialmente não antecipáveis [...]" (Schwartz, 2014, p.261).

Em uma atividade de trabalho, não raro, sacrificam-se princípios morais em nome da manutenção de um emprego por necessidade financeira, uma "arbitragem" de normas e valores que cabe ao sujeito realizar. Essa arbitragem é mediada pela comunicação organizacional, que tem, em seu cerne, o papel de identificar e combinar capacidades individuais para delinear um objetivo coletivo acordado dentro de uma organização. Essa cooperação visa suplantar as limitações biológicas, psicológicas e sociais que a individualidade confere aos sujeitos, ante o entendimento de que as organizações são, segundo 
Kunsch (2017), seres vivos e entidades dinâmicas que integram o grande sistema global e estão sujeitas a acontecimentos e interferências das variáveis ou forças sociais, políticas, econômicas, tecnológicas e ecológicas que regem o mundo.

Historicamente, a comunicação organizacional se vale das tendências comunicacionais de seu tempo para arbitrar as relações de trabalho e as relações com seus públicos de interesse. A tendência à não-linearidade e à diluição de fronteiras pressionou as organizações a aderirem ao princípio dialógico inerente às redes sociais, elegendo digital influencers para serem porta-vozes de seus produtos e serviços. Na era dos cancelamentos de marcas e personalidades, os personagens fictícios, ou brand personas, assumem o protagonismo e também os riscos das interações diretas com os públicos. A construção da personagem virtual carrega princípios da comunicação organizacional que reverberam na ergologia em relação à emulação de comportamentos e posicionamentos nas redes que conversem com os atores reais tanto da ambiência organizacional quanto do universo exterior (Morgan, 2002).

No caso que será analisado nesta pesquisa, Nat Natura, avatar de uma revendedora ("consultora") da empresa Natura \& Co, planejada para interagir com os diversos públicos da organização Natura, simula a arbitragem de normas, bem como as dramáticas do uso de si (reimaginadas a partir de um mundo ético ideal) de um corpo-si que não existe fisicamente, é uma holografia, uma ideia no éter, parte da identidade geral da marca Natura, fruto da autopoiese organizacional (Morgan, 2002). Traz em seu ethos a presteza do atendimento, os sentimentos do público e os objetivos da organização. Uma personalidade construída para dialogar com os públicos interno e externo, visando à conquista de novos espaços e de novos mercados.

Na sequência, veremos princípios da teoria enunciativo-discursiva de Maingueneau (2020) que podem auxiliar na compreensão de Nat Natura enquanto um reflexo dessa dinâmica autopoiética que, hoje, é fonte da construção discursiva organizacional.

\section{Cenografia e ethos como imagem de si na comunicação organizacional}

Toda enunciação sofre com uma limitação da ordem do gênero de discurso, ao mesmo tempo que opera sob uma dimensão construtiva do discurso (Maingueneau, 2008), ou seja, ela acontece em um espaço dado, em que "cena de enunciação" se desdobra em cenas "englobante" e "genérica", mas também encena a construção do seu próprio espaço através da "cenografia", inscrevendo o modo de dizer que o torna pertinente. A cena englobante associa o discurso a um certo tipo (publicitário, filosófico), enquanto a cena genérica o liga a um gênero ou subgênero (o editorial, o guia turístico); a cenografia, por sua vez, é responsável por instituir um espaço que valide o discurso e produza no destinatário os efeitos que o locutor pretendeu. $A$ cenografia funciona "ao mesmo tempo como quadro e como processo" (Maingueneau, 2008, p.51).

O ethos, por sua vez, passou por mudanças ao longo do tempo. 0 conceito se encontra na clássica Retórica de Aristóteles, designando a boa imagem que o orador transmite de si. Sua associação às ciências da linguagem se deve, principalmente, à teoria polifônica da enunciação de Oswald Ducrot. Em relação especificamente a Maingueneau (2020), o ethos é integrado à cenografia com objetivo de persuadir ou "seduzir" o interlocutor por meio da adesão a um tipo de cena que o enunciador intenta criar. "O destinatário constrói uma representação do locutor por meio daquilo que ele diz e de sua maneira de dizê-lo [...]" (Maingueneau, 2020, p.9). Importante notar que, quando falamos simplesmente em ethos, nos referimos ao ethos efetivo, resultado da interação entre os ethos complementares dito e mostrado; discursivo e pré-discursivo; conforme especificado na Figura 1: 
Figura 1: 0 ethos efetivo

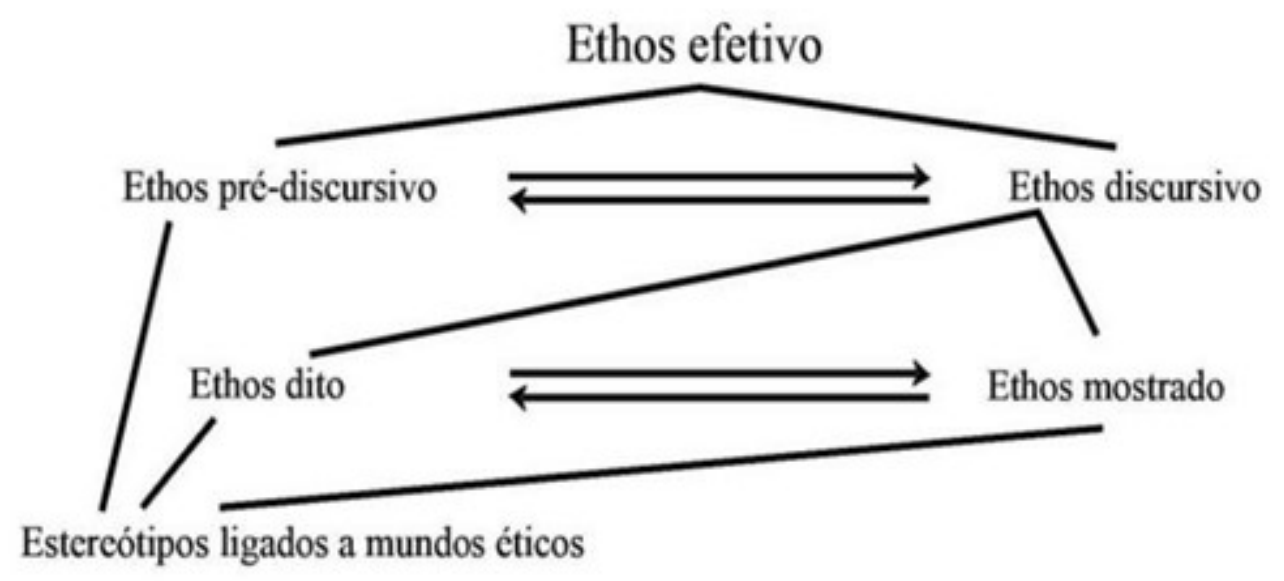

Fonte: Maingueneau (2008, p.71).

Não basta ao político, por exemplo, declarar "sou honesto, sou competente" (ethos dito). Deve-se projetar uma imagem de si (ethos mostrado) que, por sua cenografia (ethos discursivo), leve o destinatário a chegar à conclusão de que o político é honesto e capaz (ethos efetivo). 0 mesmo acontece no caso de um vendedor ou representante de uma marca: o vendedor deve projetar o ethos de alguém honesto e credível, em quem o cliente possa confiar. "Normalmente, a cenografia deve ser legitimada ou relegitimada pela própria enunciação que sobre ela se apoia [...]" (Maingueneau, 2020, p.19). Esse processo foi também denominado por Maingueneau (2005) "enlaçamento paradoxal", de acordo com o qual "o leitor que o ethos 'incorpora' de imediato à cenografia adere progressivamente ao mundo que exige essa cenografia e nenhuma outra" (p.79, grifo nosso).

A incorporação é o processo pelo qual o destinatário se apropria do ethos projetado para adentrar o que Maingueneau (2020) chama de "mundo ético". A incorporação significa a apropriação não apenas de um comportamento, mas de "uma maneira específica de se relacionar com o mundo habitando seu próprio corpo [...]". (Maingueneau, 2020, p.14). Esse discurso deve ser validado pela figura do fiador, responsável por dar acesso ao "mundo ético" do enunciador. "O destinatário constrói [...] a figura desse fiador apoiando-se em um conjunto difuso de representações sociais estereotipadas [...]" (Maingueneau, 2020, p.14). Dessa forma, o destinatário busca em um modelo (estereótipo), disponível no pano de fundo cultural dividido com seus pares em sociedade, a validação em pessoa (fiador) de certo mundo de ideias (mundo ético); para habitar esse mundo, ele deve assumir o ethos do modelo concebido discursivamente (incorporação).

Como reforça Maingueneau (2020), o ethos do sujeito denota não somente um modo de agir, mas também um modo de ser. 0 poder de persuasão de um discurso resulta, em boa parte, do fato de ele levar o destinatário a se identificar com o movimento de um corpo (Maingueneau, 2020, p.14). Do mesmo modo, é possível alicerçar força sobre o ethos de um terceiro, atribuindo a ele uma função de antagonista na cenografia do sujeito e exercendo persuasão pela oposição feita a ele. Maingueneau (2005, p.71) registra essa possibilidade como "antiethos", que, por sua vez, dá origem a um antifiador e a um mundo ético que funciona como antimodelo. Um antimodelo deve estar de algum modo ancorado sobre uma cena validada, "em que 'validada' significa 'já instalada na memória coletiva'" (Maingueneau, 2005, p.81).

No caso analisado, a empresa Natura \& Co. utiliza cenas validadas de empresas e grandes corporações impessoais e distantes do público como antimodelo para reforçar um ethos de cordialidade informal, preocupação em nível pessoal, quase intimidade, para compor um mundo ético de empresa ideal para se trabalhar e consumir. Veremos as possibilidades de amarrações teóricas em mais detalhes na sequência. 


\section{PROCEDIMENTOS DE ANÁLISE PARA CENOGRAFIA E COMUNICAÇÃO ORGANIZACIONAL EM PERSPECTIVA ERGOLÓGICA}

A pesquisa é exploratório-descritiva, bibliográfica e documental com abordagem qualitativa. 0 procedimento utilizado será o observacional e o método de abordagem, o dedutivo. Como marco teórico, parte-se de duas fundações teóricas: a ergologia, presente em Yves Schwartz (2014) e Louis Durrive (2011), e a análise do discurso de base enunciativa sóciohistórica de Dominique Maingueneau (2020). Serão articuladas a relação entre linguagem e trabalho na geração do discurso organizacional, sobretudo a questão das dramáticas de uso do corpo-si, e as noções de cenografia e ethos na análise do discurso. Pretendemos apresentar nesta seção possibilidades de aplicação teórica que a interface entre as teorias oferece para os estudos em comunicação organizacional em relação ao tipo de corpus analisado.

0 corpus é composto por posts no Twitter da brand persona Nat Natura, da empresa Natura \& Co. Nat Natura "se" define (de acordo com sua bio no Twitter) como "Consultora de Beleza Natura, Influenciadora Digital, Porta-voz da Natura aqui no Twitter, apoiadora de causas socioambientais e 'mãe' do Murumuru [gato]", conforme reproduzido na Figura 2:

Figura 2: Biografia de Nat Natura no Twitter

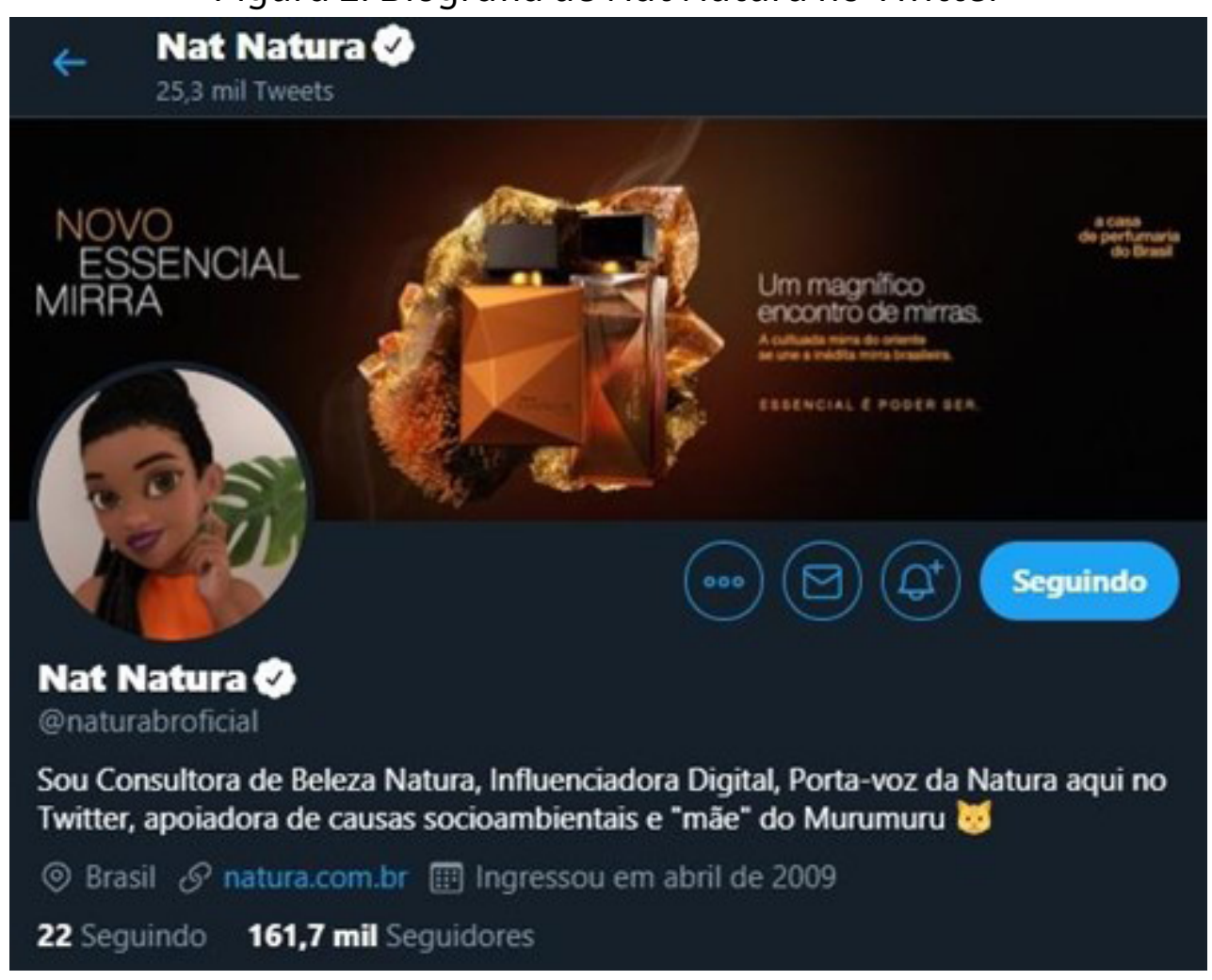

Fonte: Twitter (@naturabroficial).

Nat Natura é desenhada e animada pelo estúdio indiano Anymotion. Ela foi introduzida em 2016 como uma assistente virtual para responder dúvidas do público (ouvidoria), mas só ganhou um rosto e uma forma humana em 2018. De acordo com Paula Pimenta, diretora da Central de Relacionamento Natura, "os primeiros resultados apontam que a Nat consegue resolver os casos [...] sem perder a essência da companhia, que é um relacionamento carinhoso com nossas consultoras" (Conheça..., 2018).

Trata-se do que é conhecido em marketing e publicidade como brand persona, isto é, a sintetização dos valores de uma marca na forma de uma pessoa (Turchi, 2013). 0 Brasil conheceu ao longo dos anos casos clássicos de brand persona na era forte da publicidade na televisão (Bombril, Casas Bahia, Kaiser...). A era da publicidade nas redes sociais, por sua vez, viu 0 nascimento das "embaixadoras de marcas". Uma embaixadora da Natura ou da Avon, por um lado, é uma pessoa normal, sujeita às circunstâncias da vida nas redes, como o cancelamento através de declarações impopulares. Uma brand persona 
digital, por outro lado, é a versão ideal de uma embaixadora, sem volição própria que não seja a de promover a marca, uma representação organizacional fruto de um processo autorreferencial, autopoiético (Morgan, 2002).

Em sua biografia no Twitter, conforme a Figura 2, Nat Natura afirma ser uma "Consultora de Beleza Natura" em primeiro lugar. Desse modo, Nat Natura começa a mímica de uma atividade de trabalho que espelha a atividade real de revendedoras da empresa. A materialidade da análise é dada pela linguagem na forma de postagens (Figuras 3, 4 e 5).

Figura 3: Home office

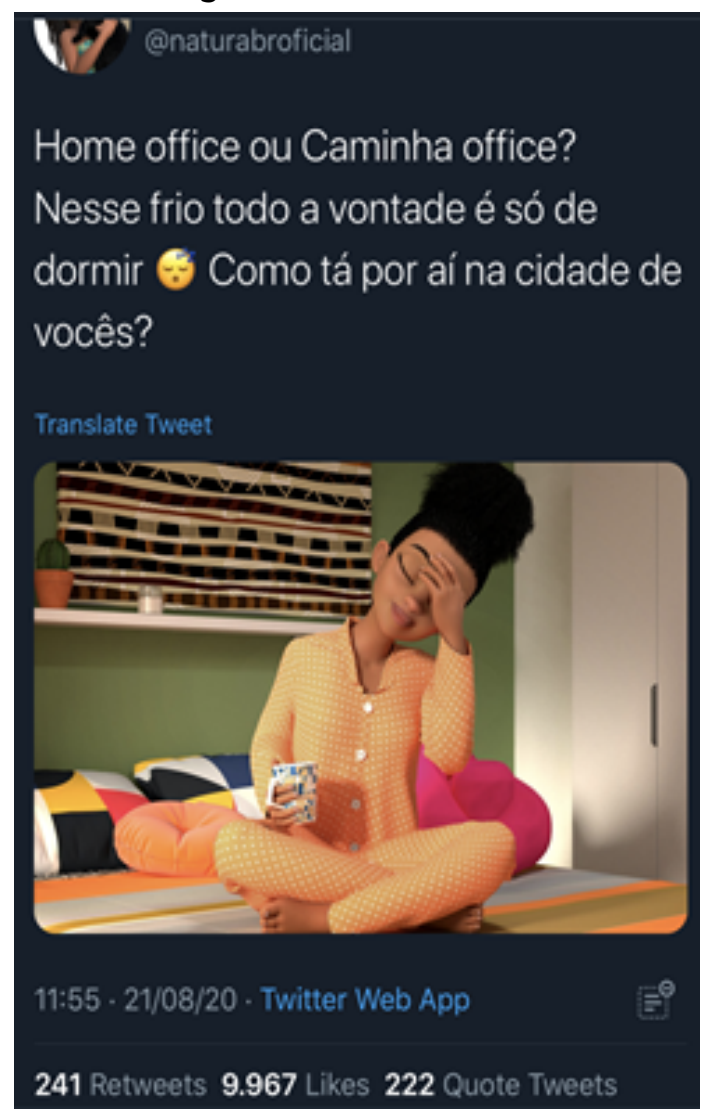

Fonte: Twitter (@naturabroficial).

Figura 4: \#TBT

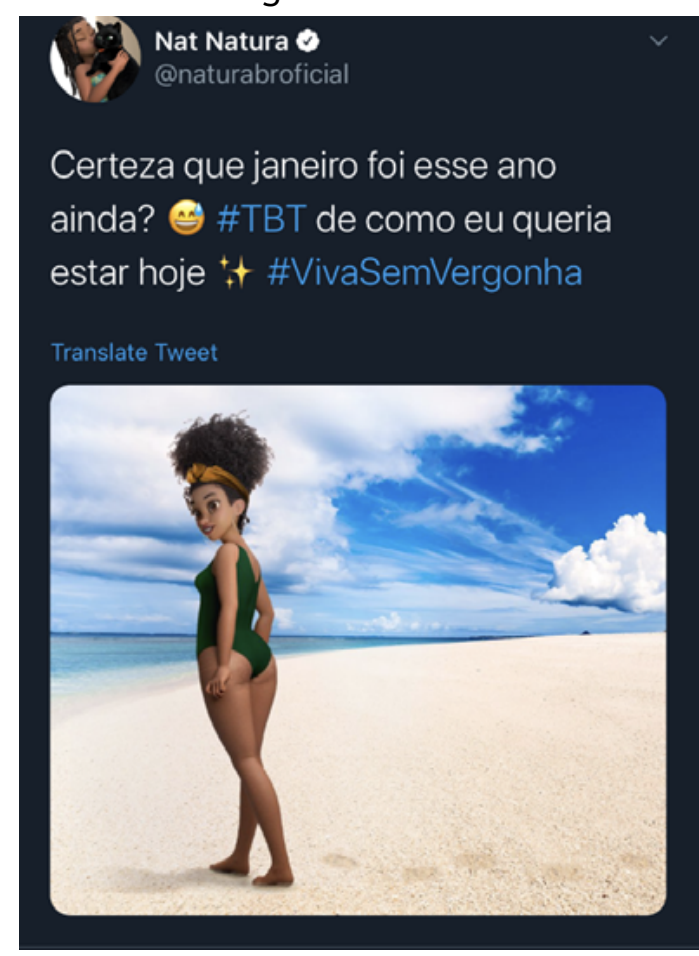

Fonte: Twitter (@naturabroficial). 
Figura 5: Aceitar os cachos

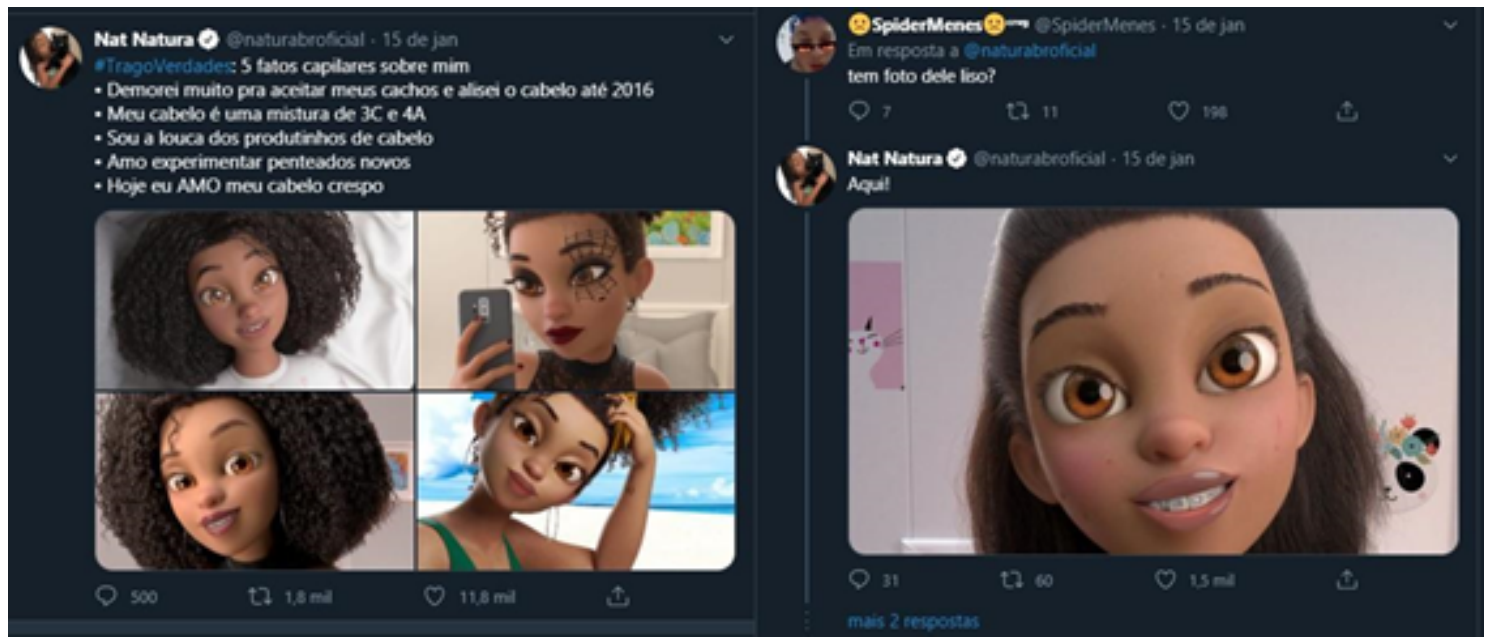

Fonte: Twitter(@naturabroficial).

A cenografia dominante nessas figuras é a de identificação e intimidade com o público: projeta-se um ethos responsável por dizer ao usuário ou usuária do Twitter "eu sou como você" e por forjar uma ilusão de intimidade. Esse é um ethos efetivo. 0 ethos pré-discursivo é composto por dados estereotípicos e mundos éticos relacionados à marca e à personagem; depõe em favor da comunicação organizacional da empresa a consistência de Nat Natura ao explorar temas como positividade corporal, saúde mental, consciência ambiental etc. Já o ethos discursivo é produto de um ethos dito, em que Nat Natura fala de si mesma explicitamente - "a vontade é só dormir" (Figura 3); "amo experimentar penteados novos" (Figura 5) -, e um ethos mostrado, em que Nat transmite certo ethos de modo implícito - "sou como você" (Figuras 3 e 4); "me amo e me aceito" (Figura 5).

Na Figura 3, Nat Natura imita posts muito comuns em 2020, durante a quarentena ocorrida devido à pandemia da covid-19, sobre a rotina de trabalho em casa. Já na Figura 4, ela lamenta o fato de não estar mais de férias ao postar uma "foto" da sua "viagem de verão". Há aqui a simulação de duas dramáticas do uso do corpo-si, pois, como sabemos, Nat Natura é uma animação, um produto de design gráfico; ela evidentemente não trabalha. Na Figura 3, Nat expõe um uso de si pelos outros ao ser forçada a administrar sua "vontade" de dormir apesar da carga de trabalho que tem em seu "home office" (por conta da pandemia), uma situação muito comum para seus seguidores. Sabemos também que "a dramática é o embate entre os valores do corpo-si e as questões impostas pelo meio" (Freitas et al., 2019, p.181), mas não há valores inerentes ao corpo-si de uma animação virtual com fins publicitários, e definitivamente não há imposições pelo meio; há, contudo, dramáticas entre valores e imposições de meio por parte do público que acompanha Nat Natura pelo Twitter, de modo que suas dramáticas fictícias servem ao propósito de construção de um ethos (Maingueneau, 2020) com o qual o destinatário irá tensionar sentidos, podendo ou não repercutir em uma identificação (Baldissera, 2010).

A cenografia intenta influenciar o público a esquecer-se temporariamente de que Nat Natura é fictícia, em uma dinâmica que é um jogo simultaneamente deliberado e espontâneo. 0 tweet da Figura 5, por exemplo, aproveita-se de uma tendência em círculos de beleza: a transição capilar, ou seja, pessoas que até então alisavam seus cabelos crespos e que passaram a assumi-los ao natural. Trata-se de uma mensagem que partilha empoderamento feminino, validação identitária racial e positividade corporal. Há, dessa forma, uma apropriação de problemáticas sociais captadas pelo processo dialógico da organização com seus públicos de interesse (Kunsch, 2017) como via rápida para disseminação de conteúdo na internet. Os posts desse tipo são consistentes com uma mensagem positiva para ganharem tração suficiente nas redes e garantirem publicidade gratuita à empresa.

Como foi antecipado, essa orientação segue em duas direções: 1) o trabalhador - buscando convencer o destinatário de que a empresa é uma boa opção para se tornar uma revendedora; e 2) o cliente e o cliente em potencial - na projeção de um ethos 
de identificação com o destinatário em que Nat Natura, uma personagem virtual, sofre com problemas do mundo real, como insegurança em relação à sua aparência. Essas questões serão exploradas através do dispositivo de análise ilustrado no Quadro 1.

Quadro 1: Dispositivo de análise ergodiscursiva para o caso Nat Natura

\begin{tabular}{|c|c|c|}
\hline Corpus & Fundamento teórico & Resultado \\
\hline $\begin{array}{l}\text { Figura } 2 \text { - Biografia de } \\
\text { Nat Natura no Twitter }\end{array}$ & $\begin{array}{l}\text { Cenografia, ethos e cena validada (Maingueneau, } \\
\text { 2005, 2020); dramáticas de uso do corpo-si (Schwartz, } \\
\text { 2010); Comunicação organizacional e autopoiese } \\
\text { (Baldissera, 2017; Kunsch, 2017; Morgan, 2002). }\end{array}$ & $\begin{array}{l}\text { Em sua biografia no Twitter, Nat Natura projeta } \\
\text { um ethos de "gente comum", construído pela } \\
\text { apropriação discursiva de grupos de interesse } \\
\text { da marca, que usa como antimodelo a cena } \\
\text { validada da empresa tradicional, impessoal. }\end{array}$ \\
\hline Figura 3 - Home Office & $\begin{array}{l}\text { Cenografia e ethos (Maingueneau, 2005, } \\
\text { 2020); Dramáticas de uso do corpo-si } \\
\text { (Schwartz, 2010, 2014); dinâmica autopoiética } \\
\text { (Baldissera, 2017; Morgan, 2002). }\end{array}$ & $\begin{array}{l}\text { Nat simula dramáticas de uso do corpo-si (trabalhar } \\
\text { no home office durante a quarentena) que } \\
\text { reverberam com discursos dos públicos interno e } \\
\text { externo da organização para gerar identificação } \\
\text { e aproximar a corporação do destinatário. }\end{array}$ \\
\hline Figura 4-\#TBT & $\begin{array}{l}\text { Cenografia e ethos (Maingueneau, 2005, } \\
\text { 2020); Dramáticas de uso do corpo-si } \\
\text { (Schwartz, 2010, 2014); dinâmica autopoiética } \\
\text { (Baldissera, 2017; Morgan, 2002). }\end{array}$ & $\begin{array}{l}\text { Nat volta a simular dramáticas de uso do corpo- } \\
\text { si ao lamentar o cotidiano e exibir uma nostalgia } \\
\text { das férias que teria passado na praia. O ethos } \\
\text { efetivo visa à identificação do destinatário; o ethos } \\
\text { pré-discursivo é consistente com uma relação de } \\
\text { intimidade forjada pela Nat com seus seguidores. }\end{array}$ \\
\hline $\begin{array}{l}\text { Figura } 5 \text { - "Aceitar } \\
\text { os cachos" }\end{array}$ & $\begin{array}{l}\text { Cenografia e ethos com ênfase na incorporação } \\
\text { do fiador (Maingueneau, 2005, 2020); Dramáticas } \\
\text { de uso do corpo-si (Schwartz, 2010, 2014). }\end{array}$ & $\begin{array}{l}\text { Como modelo de positividade, Nat estabelece-se } \\
\text { como fiadora de um mundo ético em que a Natura } \\
\text { é uma empresa que se preocupa e se importa } \\
\text { com o bem-estar das suas clientes (sem deixar } \\
\text { de ofertar produtos para a manutenção dessa } \\
\text { positividade, o que constitui um problema ético). }\end{array}$ \\
\hline
\end{tabular}

Fonte: elaborado pelos autores.

Para simulação convincente de um corpo-si situado em uma atividade de trabalho que soa real, envolvido em dramáticas fabricadas de uso de si por si e de si pelos outros, a criação da personagem passa por um processo de mímica e assimilação da realidade do trabalhador. Nesse processo, Nat Natura encena a personificação de uma empresa com consciência ecológica e motivação ideológica, apropriando-se de duas características identitárias - mulher negra - de grande potência discursiva no clima político e cultural contemporâneo, em sintonia com o alinhamento do jovem usuário do Twitter e consumidor da marca. Ao drenar a carga simbólica dessas duas características na forma de uma personagem de feições cuidadosamente desenhadas e discurso pré-renderizado, artificial, Nat se blinda com um ethos pré-discursivo forjado, captado de cenas validadas vividas por pessoas reais, para então falar com aparente legitimidade sobre problemáticas sociais.

Resulta desse processo um ethos de empresa próxima do jovem usuário. Nat Natura, surgida das disputas de sentido que marcam lutas sociais como o racismo e o machismo, agora também reconstrói significados no imaginário coletivo. Em oposição a esse ethos dito está uma cena validada em que empresas são vistas, normalmente, como corporações gananciosas cujo único objetivo é drenar o cliente de seu dinheiro. Contra essa cena validada, Nat Natura oferece um ethos mostrado de "amiga virtual" que parece estar preocupada com todas as coisas do mundo, menos com o dinheiro do cliente, como se as apreensões da empresa com o fechamento do seu ano fiscal não existissem. 


\section{CONSIDERAÇÕES FINAIS}

Nat Natura, mais do que uma brand persona que emula comportamentos em rede, dá a tônica do potencial da publicidade através do dialogismo intrínseco à comunicação organizacional. Resultado de pesquisas de comportamento nas redes sociais, em simbiose com as interações dos públicos interno e externo que orbitam a Natura \& Co, a personagem virtual é um vislumbre das potencialidades e também das fragilidades que as dinâmicas em rede impõem às organizações.

Para chegar a essas percepções, mobilizamos pressupostos teóricos da ergologia (Durrive, 2011; Schwartz, 2014) colocados em tela com preceitos da comunicação organizacional (Baldissera, 2017; Kunsch, 2017; Morgan, 2002) enquanto resultado de disputas de sentido sobre as regras e valores do mundo do trabalho que servem para a composição da personagem Nat Natura. 0 aporte metodológico foi abastecido por conceitos e categorias da análise do discurso (Maingueneau, 2020), especificamente os conceitos de cenografia e ethos do plano de enunciação. Essas possibilidades de análise são ainda incipientes e dizem respeito especificamente às figuras selecionadas. Outras direções podem e devem ser consideradas em pesquisas ulteriores. Importante anotar que a presente pesquisa terá ainda dois desdobramentos em futuro próximo, o primeiro com ênfase em ergologia, o segundo com foco na comunicação organizacional.

À luz da questão norteadora e do objetivo de pesquisa, concluímos que Nat Natura age como porta-voz para validação da empresa Natura como um bom lugar tanto para 1) o trabalhador, fazendo a mímica de dramáticas do uso do corpo-si de uma vendedora da Natura, quanto para 2) o cliente, para quem Nat funciona como a fiadora que o cliente em potencial deve incorporar para acessar um mundo ético em que a empresa é empática e está próxima do seu público, em uma relação de identificação e intimidade. Do ponto de vista da comunicação organizacional, como já destacado, essa conclusão nos leva ao seguinte resultado: a empresa Natura \& Co. incorpora ao discurso organizacional sentidos construídos a partir de uma dinâmica autopoiética para apagar e substituir seu ethos de corporação por um ethos de pessoa física com o qual seus clientes podem se identificar para angariar apoio e publicidade gratuita no Twitter.

\section{REFERÊNCIAS}

BALDISSERA, Rudimar. Comunicação organizacional e imagem-conceito: sobre gestão de sentidos no ambiente digital. In: RUÃO, Teresa; NEVES, Ronaldo; ZILMAR, José (ed.). A comunicação organizacional e os desafios tecnológicos. Braga: CECS, 2017. p.71-87.

BALDISSERA, Rudimar. Organizações como complexus de diálogos, subjetividades e significação. In: KUNSCH, Margarida M. Krohling (org.) A comunicação como fator de humanização das organizações. São Caetano do Sul: Difusão, 2010. p.61-76.

CONHEÇA a Nat, a assistente virtual da Natura. Natura, São Paulo, 26 nov. 2018. Disponível em: https://www.natura.com.br/ blog/mais-natura/conheca-a-nat-a-assistente-virtual-da-natura. Acesso em: 12 set. 2020.

DURRIVE, Louis. A atividade humana, simultaneamente intelectual e vital: esclarecimentos complementares de Pierre Pastré e Yves Schwartz. Trabalho, Educação e Saúde, Rio de Janeiro, v.9, suppl.1, 2011.

FREITAS, Ernani Cesar de et al. A construção do ethos discursivo corporativo: 0 uso de si e noção de competência. Moara, Belém, n.51, p.175-196, 2019. 
KUNSCH, Margarida. Comunicação organizacional: aportes teóricos e metodológicos. In: MARQUES, Angela; OLIVEIRA, Ivone de Lurdes; LIMA, Fábia (org.). Comunicação organizacional: vertentes conceituais e metodológicas. Belo Horizonte: PPGCOM/ UFMG, 2017. p.41-53.

LUHMANN, Niklas. Sistemas sociais. Esboço de uma teoria geral. Petrópolis: Vozes, 2016.

MAINGUENEAU, Dominique. Cenas da enunciação. São Paulo: Parábola, 2008.

MAINGUENEAU, Dominique. Ethos, cenografia, incorporação. In: AMOSSY, Ruth (org.) Imagens de si no discurso: a construção do ethos. São Paulo: Contexto, 2005. p.69-92.

MAINGUENEAU, Dominique. Variações sobre o ethos. São Paulo: Parábola, 2020.

MORGAN, Gareth. Imagens da organização. 2.ed. São Paulo: Atlas, 2002.

SCHWARTZ, Yves. Motivações do conceito de corpo-si: corpo-si, atividade, experiência. Letras de Hoje, Porto Alegre, v.49, n.3, p.259-274, 2014.

SCHWARTZ, Yves. Trabalho e ergologia. In: SCHWARTZ, Yves; DURRIVE, Louis (org.). Trabalho e ergologia: conversas sobre a atividade humana. 2.ed. Niterói: Ed. UFF, 2010. p.25-46.

SCHWARTZ, Yves; DURRIVE, Louis (org.). Trabalho e ergologia: conversas sobre a atividade humana. 2.ed. Niterói: Ed. UFF, 2010.

SCHWARTZ, Yves; ECHTERNACHT, Eliza Helena. 0 trabalho e a abordagem ergológica: "Usos dramáticos de si" no contexto de uma central de tele-atendimento ao cliente. Informática na Educação: Teoria \& Prática, Porto Alegre, v.10, n.2, p.9-24, 2007.

TRINQUET, Pierre. Trabalho e educação: o método ergológico. Revista HISTEDBR On-line, Campinas, v.10, n.38, p.93-113, 2010.

TURCHI, Sandra. Persona da marca: parte importante da estratégia nas mídias sociais. 2013. Sandra Turchi, São Paulo, 16 ago. 2013. Disponível em: http://sandraturchi.com.br/persona-da-marca-parte-importante-da-estrategia-nas-midias-sociais-2/. Acesso em: 26 abr. 2021.

Artigo recebido em 29.04.2021 e aprovado em 09.08.2021. 